\title{
Autonomous Robotics and the Laws of War: Methods and Consequences of Regulating Artificial Intelligence in Warfare
}

\author{
Joshua E. Duke
}

\begin{abstract}
This article addresses the question of what impact International Humanitarian Law (IHL), the Laws of Armed Conflict (LOAC), and the international community can or should have on the international development/deployment of autonomous and semi-autonomous weapon systems, and how the international community can achieve a significant impact with emerging national or cooperative international regulations or laws with regards to the developing relationship between robotics and warfare, without hindering technological developments in other areas of human life. The author, using primarily case studies related to weapon autonomy and robotics in warfare, tests the following theory: Technological advancements related to the development and implementation of autonomous and semi-autonomous weapons in warfare have the potential to be directly impacted by IHL and the LOAC, by using a reactive approach guided by historical underlying principles related to other technologies and the moral spirit of existing laws in order to proactively regulate the field. In testing the theory, the author shows the differences in lasting and effective technological impact of reactive versus proactive international actions. The case studies highlight the effectiveness of reactive international action, while framing the underlying issues of the past in the context of modern autonomous weaponry developments. The article highlights the record of weapon systems with autonomous functions and discusses fully autonomous lethal weapon systems' inherent inability to comply with international human rights laws.
\end{abstract}

Keywords: Artificial Intelligence, autonomous weapons, international law, warfare, human rights, LOAC, United Nations 


\title{
La robótica autónoma y las leyes de la guerra: métodos y consecuencias de regular la inteligencia artificial en la Guerra
}

\begin{abstract}
RESUMEN
Este artículo aborda la cuestión de qué impacto pueden o deben tener el Derecho Internacional Humanitario (DIH), las Leyes de los Conflictos Armados (LOAC) y la comunidad internacional en el desarrollo / despliegue internacional de sistemas de armas autónomos y semiautónomos, y cómo La comunidad internacional puede lograr un impacto significativo con las regulaciones o leyes nacionales o cooperativas internacionales emergentes con respecto al desarrollo de la relación entre la robótica y la guerra, sin obstaculizar los desarrollos tecnológicos en otras áreas de la vida humana. El autor, utilizando principalmente estudios de casos relacionados con la autonomía de las armas y la robótica en la guerra, prueba la siguiente teoría: Los avances tecnológicos relacionados con el desarrollo y la implementación de armas autónomas y semiautónomas en la guerra tienen el potencial de verse directamente afectados por el DIH y la LOAC. , mediante el uso de un enfoque reactivo guiado por principios históricos subyacentes relacionados con otras tecnologías y el espíritu moral de las leyes existentes para regular proactivamente el campo. Al probar la teoría, el autor muestra las diferencias en el impacto tecnológico duradero y efectivo de las acciones internacionales reactivas frente a las proactivas. Los estudios de caso destacan la eficacia de la acción internacional reactiva, al tiempo que enmarcan los problemas subyacentes del pasado en el contexto de los desarrollos armamentísticos autónomos modernos. El artículo destaca el historial de los sistemas de armas con funciones autónomas y analiza la incapacidad inherente de los sistemas de armas letales totalmente autónomos para cumplir con las leyes internacionales de derechos humanos.
\end{abstract}

Palabras clave: Inteligencia artificial, armas autónomas, derecho internacional, guerra, derechos humanos, LOAC, Naciones Unidas 


\section{自主机器人技术与战争法: 在战争中 管理人工智能的方法和结果}

摘要

本文研究了一个问题, 即国际人道主义法（IHL）、武装冲突 法（LOAC）和国际社区能对或应该对国际开发/部署自主及 半自主武器系统产生什么影响; 以及在不阻碍人类生活其他 方面的技术开发的同时, 国际社区如何通过 “就发展机器人 技术和战争之间的关系而制定的国家规制、国际合作规制或 法律”, 进而实现显著影响。作者主要使用与战争武器自主 和机器人技术相关的案例研究, 检验以下理论: 与 “开发和 执行自主及半自主战争武器” 相关的技术进步有可能通过反 应式措施（reactive approach）而受到IHL和LOAC的直接影 响, 这种措施由 “与其他技术相关的历史原则及现有法律的 道德观” 所引导, 以期主动监管该领域。在测试该理论的过 程中, 作者表明了反应式与主动式国际行动在持久且有效的 技术影响方面存在的差异。该案例研究强调了反应式国际行 动的有效性, 同时在现代自主武器开发情境下对过去潜在的 问题加以定义。本文强调了具有自主功能的武器系统的相关 记录, 并探讨了全自主致命武器系统无法遵从国际人权法这 一内在缺陷。

关键词: 人工智能, 自主武器, 国际法, 战争, 人权, 武装 冲突法, 联合国

Just because something doesn't do what you planned it to do doesn't mean it's useless.

\section{Introduction}

7 hroughout the history of warfare, technological advances have consistently created invaluable combat advantages to those who possess them, and as technologies have advanced, warfare has steadily become more automated and less proportionate, often resulting in human rights being sidelined in the process. Since their recognition in the international community, International Humanitarian Law (IHL) and the Laws of Armed Conflict (LOAC) have repeatedly found relevance in debates surrounding tech- 
nological inventions and advancements, leading to multiple international conventions and treatises codifying the morality of mankind into what the world recognizes in the modern day as basic human rights - laws that supersede warfare, and which have become a primary underlying moral cause that unites the world in peace even in times of war. When technological developments have the potential to inherently contradict human rights or the laws of war, the international community has formed a habit of moral interference for the sake of mankind, from banning the installation of nuclear weapons in space, ${ }^{1}$ to stigmatizing entire categories such as chemical weapons. ${ }^{2}$ Recent and potential future developments in the fields of robotics and Artificial Intelligence (AI), specifically as they can be applied to warfare, have sparked a similar debate with regards to applications of robotics with autonomous functions in warfare as they relate to IHL and the LOAC.

The application of lethal autonomous functions to technology in warfare is not a new phenomenon, as the 1907 ban on automatic submarine contact mines shows. ${ }^{3}$ While technologies have certainly advanced exponentially since that time, the guiding underlying principles of IHL and the LOAC, clearly evident in the content and intent of the 1907 ban, are the same underlying principles governing the technological applications of autonomy in warfare today. The primary difference is the evolution from automatic functions to autonomous and adaptive AI functions, which essentially have the power to give full or partial decision-making authority over the life and death of humans to machines. A major factor essential in framing the impact and effectiveness of international community IHL or LOAC-centric debates over autonomy in warfare, depends on whether the debate is reactive or proactive in its approach, regardless of the specific topic. This article addresses the question of what impact IHL, the LOAC, and the international community can or should have on the international development/deployment of autonomous and semi-autonomous weapon systems, and how significant impact can be achieved with regards to the developing relationship between robotics and warfare.

Technological advancements related to the development and implementation of autonomous and semi-autonomous weapons in warfare have the potential to be directly impacted by IHL and the LOAC. Using a reactive approach guided by historical underlying principles related to other technologies and the moral spirit of existing laws in order to proactively regulate the field can illustrate the differences in lasting and effective technological impact of reactive versus proactive international actions-Actions taken after events have occurred, versus actions taken to prevent events that may be possible. The case studies highlight the effectiveness of reactive international action, while framing the underlying issues of the past in the context of modern autonomous weaponry developments. The debate over the future of autonomous robotics in warfare contains both reactive and proactive elements. 
Some weapon systems with autonomous functions have already existed long enough to have a significant track record to examine from a reactive perspective, while the proactive side of the debate focuses primarily on potential fully autonomous lethal weapon systems being deployed in the future, and their as yet inherent inability to comply with IHL and the LOAC.

\section{Theory and Methodologies}

I $\mathrm{n}$ order to show the effective and reactive nature of the international community when addressing technological developments for warfare with IHL/LOAC implications, two case studies are presented in this article, as well as a theoretical application of adaptive AI to future combat scenarios to highlight the potential negative impact of a proactive general ban in the field of autonomy in robotics. The first case study compares persistent free-floating naval mines and anti-personnel mines, which were banned by The Hague VIII Convention Relative to the Laying of Automatic Submarine Contact Mines (The Hague VIII Convention), ${ }^{4}$ and the 1997 Convention on the Prohibition of the Use, Stockpiling, Production and Transfer of Anti-Personnel Mines and on their Destruction (Mine Ban Treaty), ${ }^{5}$ respectively, to modern day autonomous and semi-autonomous weapon systems. The purpose of this first case study is to draw comparisons between these weapons relative to the application of proportionality and distinction required for compliance with IHL and the LOAC. A comparison of the indis- criminate nature of free-floating naval mines and anti-personnel mines, and the machine decision-making process in autonomous and semi-autonomous weapon systems, also highlights the underlying nature of the IHL/LOAC implications involved in the modern debates over fielding such weapons without appropriate levels of human control.

This first case study also highlights the effectiveness of reactive international actions and emphasizes the need for the international community to have an abundance of historical information before making such a decision, as well as widespread support for it to achieve significant impact. The mine bans offer further international security insights into the reasoning behind banning or regulating technologies with IHL/LOAC implications and highlight enforcement problems which come from attempting to pursue a high impact solution to a possible future problem. A second case study examines the development and deployment of automated robotics, such as unmanned aerial vehicles (UAVs), in combat situations, and compares these human-controlled robots to computer-controlled robots, while exploring the area in between the two where adaptive AI functions create ambiguity with regards to positive human control, and subsequently with the ability to apply IHL mandates of distinction and proportionality in combat. While UAVs have set a precedent for robotic warfare, as autonomous functions are developed and implemented into them their acceptance is becoming more and more 
controversial. Comparing the properties and functions of UAVs to other existing and potential autonomous and semi-autonomous weapon systems supports the theory that proactive international actions regarding such weapons can only achieve effective and substantive significant impact in the future by framing the action reactively based on historical precedents.

Finally, a theory is proposed concerning adaptive AI research and how the international debate could inadvertently hinder beneficial technological developments. Adaptive AI research will potentially lead to machine logic, reasoning, emotion simulations, sensory simulations, and cognitive simulations comparable to, or which exceed, humans, making future AI systems potentially legally liable for their own actions, and potentially more capable of IHL/ LOAC compliance than humans. Conversely, adaptive AI research may inadvertently result in machines learning things that are averse to the objectives of those employing it, contradictory to IHL and the LOAC, or even anti-mankind. This examination of current and potential adaptive AI technologies and their applications shows the wide range of private sector and military applications potentially enhanced by the field, and how they might be impacted by the international community. A cost/benefit analysis of advancing warfare-based $\mathrm{AI}$ and autonomous robotics research subsequently provides insight into the realities of the two extremes of either pursuing these technologies wantonly, or banning them entirely.
Information to address the hypotheses was gathered primarily from historical comparisons of related events, through scholarly journals, Government, organizational, and institutional publications. Ongoing debates related to the subject of autonomy in warfare and legal precedents examining relevant areas of IHL/LOAC were also examined through primary source legal documents governing IHL/LOAC. An examination of national policies of the United States with regards to autonomy in warfare, such as the United States Defense Science Board Summer Study on Autonomy (2016), ${ }^{6}$ also provided insight into the direct impact that international debate and action can have around the world. Advanced research and development projects are not entirely public, which limited the scope of the author's research to information available in the public domain, making any conclusions dependent on the non-existence of classified variables which might affect them.

\section{Defining the Environment}

\section{What is Autonomy?}

utonomous weapon systems,
according to the United States,
are weapon systems which can identify targets, select targets, and engage targets without human interface, including weapon systems which are dormant until activated by a human counterpart, and which once activated perform the above listed functions without further human interface. Semi-autonomous weapon systems, also according to the United States, are weapon 
systems which contain one or more of the above listed functions, but which require human interface before each target engagement, or continual human interface throughout its activities, including the retention of an interruption feature, giving the human counterpart the power to stop any action of the system immediately at any time. Adaptive AI functions refers to machine learning capabilities which allow machine adaptations to environments and circumstances without human interference. While adaptive AI functions have the potential to degrade human quality and control over the machine to verify and validate the machine's actions, they also have the potential to increase combat environment flexibility and adaptability to complex combat situations automatically. One of the primary issues in the international debate over the future of autonomous technologies is the lack of a unified definition of autonomy to which all nations subscribe.

\section{Achieving Significant Impact}

Reactive and proactive refer to the context within which the international community takes up a subject for debate and produces subsequent actions. The Hague VIII convention discussed below, for example, came into existence because of a problem that already existed with deployed weapons that were indiscriminate in their nature and often resulted in non-combat casualties. This reactive approach by the international community directly impacted the weapon system, resulting in a global ban on specific weapon functions. However, efforts to proactively ban development or deployment of other weapons have not been as effective and will likely continue to be ineffective until something happens which causes the international community to react to such weapon systems. Significant impact refers to the effectiveness of the International community in its actions, including establishing international laws, garnering widespread support for such laws after they are established, and influencing which nations sign any resulting binding treaties. Significant impact has rarely been achieved by proactive international actions without historical precedents to support them.

Current and recent international debates surrounding the applications of autonomy in warfare, opinions of experts, relevant Government and organizational documents, and publications related to the subject have informed this research project. One goal of the research was to determine specifically how IHL and the LOAC apply to weapon systems with one or more autonomous functions in warfare. Robotics with adaptive AI functions in warfare have the potential to be of a higher caliber than possible for humans to achieve by themselves, leading to fewer innocent bystander casualties, and more humane warfare in general. However, machines are still currently, and possibly perpetually, inherently incapable of understanding IHL and the LOAC to an extent possible for them to replicate appropriate levels of distinction and proportionality in combat. Ultimately, this article demonstrates the need for pursuit, or at least the non-hindrance, 
of autonomous robotics research and development in order for any potential international action to succeed. To achieve significant impact, substantial and persistent oversight must also be maintained, designed to both inform and facilitate any necessary reactive international approach to future developments, and to prevent a damaging proactive ban encompassing the research and development of adaptive AI or autonomy in robotics.

\section{The Current Debate}

\section{Distinction and Proportionality}

$\mathrm{I}$ $\mathrm{n}$ any discussion of autonomy in warfare, it is important for the international community to collectively distinguish what constitutes autonomy, and more specifically, what the terms autonomous and semi-autonomous mean when referring to technologies in general, and weapon systems in particular. In the most commonly applied definitions, autonomous technologies operate by themselves automatically, without need of human interaction once activated and set to perform a task. When applied to a weapon system, this would include all of the functions required for combat, up to and including identifying targets, and engaging them. There are currently no fully autonomous weapons systems deployed in the world which are designed for engaging humans in combat. Semi-autonomous technologies are those which have one or more automatic functions programmed, but which cannot operate completely without human assistance. When applied to a weapon system, semi-autonomous includes any weapon system which performs automatic combat related functions up to, but not including, target engagement. The American Phalanx CWS and the Dutch Goalkeeper, which automatically identify, target, and engage incoming projectiles, are examples of autonomous weapon systems, but do not engage human targets, ${ }^{7}$ while UAVs like the MQ-9 Reaper are examples of semi-autonomous weapon systems which require human input in order to engage a target. ${ }^{8}$

Much of the international debates that have occurred over time related to autonomous functions in weapon systems have revolved around the definition, or lack of definition, of these terms. When it comes to complex and contentious technological issues such as autonomy, it is important to clearly understand the implication of the underlying details. Understanding and clarifying definitions in international debates has often been the underlying structural formation that ends up dictating the outcomes of treaties and conventions on weapons. In defining autonomy, Heather Roff points out that different nations have different definitions of autonomy. ${ }^{9}$ France, for instance, takes the stance that no technology is considered fully autonomous unless it operates without human control, independently, with its own decision-making process. ${ }^{10}$ Limiting the term to this narrow and explicit view provides a very large amount of room for research and development to expand and grow around any constraints placed on autonomous weaponry, while at the same time allowing autonomous functions 
in weaponry to be enhanced right up to the point of full autonomy. Under such a definition, proximity mines and other automated indiscriminate devices which automatically engage targets once activated would ascend to the title of autonomous, while semi-autonomous UAV's and other human-operated robotics would not.

Other leading experts in autonomy, such as Kenneth Anderson and Matthew Waxman, fear that a ban on autonomous weapons may inadvertently, or intentionally, end up encompassing many of the functions currently labeled as semi-autonomous. ${ }^{11}$ This fear is justified, at least in part, simply based on Switzerland's definition of autonomous weapon systems which already encompasses semi-autonomous systems. ${ }^{12}$ In arguing this point, Noel Sharkey points out that some semi-autonomous weapon systems merely provide their human counterparts with the illusion of control, where the machine itself suggests targets, and extracts approval from an automated human cognitive process, rather than the intentionally deliberative process required to appropriately meet IHL requirements. ${ }^{13}$ One of the primary factors in IHL and the LOAC is the requirement for those engaging in combat to exhibit appropriate levels of distinction and proportionality. According to Sharkey, this is a solely deliberative undertaking, and one which is subverted when relegated to an automatic human judgement based on machine-generated suggestion. ${ }^{14}$ In other words, a situation where machine-suggested targets are approved for engagement by a human in a non-deliberative way, Sharkey argues, essentially equates to the same thing as an autonomous weapon system, and should be labeled as such. ${ }^{15}$

Another part of the autonomy debate is AI, and adaptive AI functions-machine learning capabilities. Ultimately, machines can only adapt to situations they have been programmed to adapt to, which limits adaptive AI functions to programmed adaptations to anticipated situations or environments. Science fiction has convoluted the truth surrounding adaptive AI, as Sharkey points out, leading to an AI mythology that has erroneously worked its way into the official international debate on the subject. ${ }^{16}$ Cyber defense mechanisms are programmed to adapt to attacks on the systems they protect, but they are unable to adapt to an unknown attack, which is why all virus protection programs need to be constantly updated with new information as new attacks are learned about. The same is true with combat robotics programmed with adaptive AI functions. Any potential autonomous or semi-autonomous weapons system with adaptive AI placed into a field environment, Human Rights Watch asserts, will only adapt in ways it has been programmed to adapt. ${ }^{17}$ This can create advantages, but also unpredictability, because it is nearly impossible to predict with one hundred percent accuracy how the adaptive AI system will interpret the situation, and it is highly unlikely that it will interpret the situation in the same way as a human, or human programmer. ${ }^{18}$ 
In examining the potential applicability of adaptive AI functions to IHL and the LOAC, autonomy experts have made some intriguing, and sometimes contradictory, assessments. Philosopher Peter Asaro, for example, asserts that there is no possibility now or ever in the future for any programmed system to be capable of the amount of deliberation and humanity necessary to make combat decisions which comply with the IHL requirements of distinction and proportionality. ${ }^{19}$ Asaro further explains that compliance with IHL specifically is a uniquely human requirement which cannot be delegated to an automated or autonomous machine, and that therefore any machine which is programmed to autonomously perform tasks regulated by IHL should be illegal. ${ }^{20}$ This line of thought is a strong echo of the 1907 Hague VIII Convention, and the more recent 1997 Mine Ban Treaty. Roff's research supports Asaro's belief through a qualitative analysis on Jus ad Bellum proportionality, concluding that even in a controlled theoretical combat environment, autonomous weapon systems are incapable of achieving appropriate levels of proportionality to meet IHL. ${ }^{21}$

Human-controlled robotics with adaptive AI functions blur the line of distinction between autonomous and semi-autonomous, especially when the ratio between adaptive AI decision-making and human counterpart decision-making is ambiguous. In pursuit of adaptive AI applications to military technologies, Ron Arkin explains how the research and development of adaptive AI can eventually lead to autonomous weapon systems which com- ply with IHL and the LOAC better than humans. ${ }^{22}$ As sensor and programming technologies advance, Arkin sees a future where a machine programmed with IHL and the LOAC will be technologically capable of the appropriate levels of distinction and proportionality to engage autonomously in combat operations..$^{23}$ By a combination of calculations, and enhanced sensor technologies which can use a combination of information inputs to distinguish between combatants and non-combatants, an autonomous weapon system with effective and proven adaptive AI functions would, Arkin posits, be the only way to conduct humane warfare in the future. ${ }^{24}$ The inherent issue in this theory is that it requires relegating human lives to a mathematical value for the purpose of programming proportionality into an autonomous weapon system. What is the mathematical value of one human life? Can there be one? Should there be one?

\section{Context Matters}

As the international community has grown, those involved have made attempts to mitigate present and future conflict through two general approaches-reactive and proactive. In the wake of negative major world events or circumstances, the international community has developed a trend of reacting by implementing or attempting to implement measures, usually in the form of treaties or conventions, to protect against a similar event or circumstance happening in the future. While this is technically a proactive approach to ad- 
dressing a potential future conflict, the context of the governing treaty or convention is often inherently reactionary and focused on specific historical circumstances or innovations. The 1907 ban on automatic submarine contact mines, for example, as well as the 1997 treaty banning anti-personnel mines, are examples of international actions regarding existing technologies based on historical precedents. This type of international action is reactive, despite its potential proactive impact on future situations.

A large area of the autonomous weapon system debate rests on whether or not the international community and individual state governments should implement a proactive ban on the research, development, and deployment of autonomous weapon systems, as advocated by Sharkey, ${ }^{25}$ Asaro, ${ }^{26}$ and others. However, autonomy in robotics is not as clear cut as nuclear weapons in space, or laser weapons designed to blind enemy combatants. The entire field of autonomous robotics research bleeds into nearly every realm and aspect of human life on Earth. Proactively regulating a field with such a diverse impact, Anderson and Waxman argue, risks inadvertently affecting developments in a variety of other fields, including combat support as well as engagement. ${ }^{27}$ To prevent this, Anderson and Waxman suggest an incremental reactive approach, where any regulations on the field of autonomy in robotics are implemented as the technologies are developed, not before. ${ }^{28}$ Arkin differs from Anderson and Waxman in that Arkin believes the field of autono- my in robotics should be fully pursued without regulations, ${ }^{29}$ while Anderson and Waxman see regulations, short of a ban, as a necessity moving forward, in order to preserve the integrity of IHL and the LOAC within any developed autonomous warfare systems. ${ }^{30}$

A number of organizations have also become involved in the international debate over autonomous robotics. Many of the organizations promote banning all aspects of autonomous weapons altogether, as they see no way for machines to appropriately judge a situation which could result in the death of a human. The Campaign to Stop Killer Robots is an activist organization created by Human Rights Watch, leading the fight to ban autonomous weapon systems. They have support from the International Human Rights Council (IHRC) and some leading members of the United Nations Human Rights Council (UNHRC), including former special rapporteur on extrajudicial, summary or arbitrary executions, Christof Heyns, who proposed all nations place a moratorium on Lethal Autonomous Robots (LARs) in 2013.31 Many individuals have taken a stance for moving research and development on autonomy forward as well, some to promote more humane war, some to promote more effective and accurate combat capabilities, and some to promote machine war instead of human war, where the autonomous weapons systems do not target humans at all, only other machines.

This current debate has been directly impacted by historical reactive and proactive international actions, 
and regardless of which side of the debate people are on, moving forward will require additional international actions. In order to achieve a significant impact, two key requisites will need to be achieved, according to historical precedents: 1.) Wide international inclusion and acceptance of whatever terms are reached, particularly from the great powers; and 2.) Factual evidence supporting the terms, including the rationale behind their development, and assurance that such terms will not negatively impact non-related areas of human activity.

\section{$\mathrm{X}$ \# of Human Lives $=$ 3.14159265359 \\ Solve for X}

W hile comparing the international debates over mines and autonomous weapons is a comparison of a reactive international action to a potential proactive international action, the qualities inherent in the technologies are very similar from an IHL and LOAC standpoint. Once activated, free-floating automatic submarine contact mines meet all of the basic classifications of an autonomous weapon system as it is generally defined today - they are no longer controlled by a human, they select their targets without assistance, and they engage their targets upon contact without human direction. They also exhibit the worst possible qualities of an autonomous weapon they are absolutely indiscriminate, and cannot measure proportionality, thereby rendering them inherently contradictory to IHL and the LOAC. In order to achieve the reactive international action that resulted in these weapons being banned, historical evidence was provided that proved these worst traits, something which cannot be done in the present autonomous weapons system debate. A ban on autonomous weapon systems today would be a proactive international action with no historical precedent directly implicative to the types of autonomous systems being discussed.

A truly proactive international action is one which is taken in order to prevent or change a future occurrence, without a historical precedent governing its existence or implementation. An example of a proactive international action is a regulation governing a weapon system which is theoretical, in research and development phases, or which exists already, but which has not been deployed in a combat environment. The 1995 preemptive Protocol on Blinding Laser Weapons was a proactive international action. ${ }^{32}$ Article IV of the Treaty on Principles Governing the Activities of States in the Exploration and Use of Outer Space, Including the Moon and Other Celestial Bodies (Outer Space Treaty), banning the installation of nuclear weapons in space or on celestial bodies, ${ }^{33}$ was also a proactive international action. Neither of these actions were taken based on historical precedents, but on the theoretical future implications of inaction. Additionally, neither of these specific proactive international actions had a significant potential to impact any area of human life other than nation-state military activities. 
The level of impact that international actions have had has varied, from little to no effect, to significant and long-lasting impact. The most significant impacts have come from reactive international actions, not proactive actions. A number of variables affect the level of impact an international action will have, with the primary variable being the nations who agree to any international action, including not just the number, but also which nations participate. While the 1995 blinding laser weapon ban is an example of a significant impact created by a proactive international action, it is the exception, not the rule. Reactive international actions drawing from real-world examples to justify the actions provide the incentives necessary for nations to agree in most cases. Automatic submarine contact mines, for example, were creating a clear and present danger to commercial shipping, for all nations, which provided the necessary incentive for all of the major sea-faring powers to agree that all necessary precautions should be taken to protect everyone's commercial shipping interests. Which nations agree also matters, and it is unlikely that The Hague VIII Convention would have been as impactful if even one of the major sea-faring powers had not signed.

The 1997 Mine Ban Treaty provides an example of the lack of efficacy which results when major powers do not agree to participate in international actions. The United States, Russia, and China are not parties to the Mine Ban Treaty, ${ }^{34}$ and the problem of anti-personnel landmines has largely remained unaddressed in many parts of the world, despite populous movements and more than one hundred governments working to fight them. The Hague VIII Convention on the other hand was a reactive international action widely accepted and supported by all major powers and was so effective that it remains in force today, more than a century later, regulating even modern-day sea mines. Part of its long-term success is due to the language used, which encompasses the principles behind the devices, in addition to being specific to technical specifications of the devices themselves. An international action addressing autonomous weapon systems can be influenced by the principles outlined in The Hague VIII Convention and the Mine Ban Treaty, where the qualities of distinction and proportionality required for IHL conformance were as relevant and as central to the debate as they are today.

Autonomous weapon systems are comparable to persistent free-floating mines and anti-personnel mines in several respects, particularly with regards to aspects of their operation relevant to IHL and the LOAC. Autonomy research and development in the sub field of adaptive AI functionality has not progressed far enough to equate machine learning to human reason and situational deliberation. Until this happens, machines, even highly automated machines, are still machines, and are subject to the same limits of distinction and proportionality of automatic contact mines. Fielding such weapons also creates the same type of danger to non-combatants that sea mines did in the early twentieth century, where 
targets could be selected and engaged in an indiscriminate manner without human control or direction. Semi-autonomous weapon systems are a different animal. The primary difference in today's semi-autonomous weaponry from mines is human control and direction, and so long as these qualities are maintained, a weapon system is not autonomous, as the human controller of a semi-autonomous UAV can still implement the required elements of distinction and proportionality into the combat environment.

Remote-controlled robotic combat systems arguably are the starting point from which the idea of autonomous weapon systems has grown, but there are substantial differences between these types of systems, both in their compliance with IHL and the LOAC and in their operational capacities. To start, any remote-controlled system inherently retains a human factor in some way, while an autonomous system may not. By retaining a human factor for deliberation in combat situations, the machine is not responsible for compliance with IHL or the LOAC, just as a rifle cannot be responsible for such compliance. Because of this distinction, a UAV operator, not the UAV itself, is clearly responsible for the actions of the UAV, including combat activities which result in loss of life. Automation blurs this distinction, even when human control remains in place, and adaptive AI has the potential to blur it even more. As programming and sensor capabilities grow, more and more processes within human-controlled weapon systems can be delegated to the system.
Regardless of how much programming and sensor technologies improve however, machines are likely to remain permanently incapable of being self-aware to the point of humanity, or of understanding the concepts of life and death to the point of morality. Removing humans from the lethal decision-making process may therefore equate to removing humanity from warfare.

Keeping a human within the decision-making process may become more of a type of plausible deniability necessity rather than a positive control element in future robotic weapons systems. As automation increases in a human-controlled system, the operator inherently relinquishes power to the machine, incrementally over time. Human trust in equipment may also lead to errant automated judgment calls being accepted and acted upon by a human controller, leading to a semi-autonomous weapon's pseudo-decisions being a major factor in the deliberative step required for IHL compliance. Targeting systems have already demonstrated this problem, known as automation bias, where a human operator accepts incorrect targeting suggestions from a weapon system program simply because the system determined which targets were the best ones, and the operator trusts the machine. ${ }^{35}$ The best way to avoid this pitfall is to ensure operator training includes enhancing awareness of this risk, and differentiation between machine and human deliberative capabilities, specifically to highlight the necessity for human deliberation to comply with the IHL requirements of distinction and proportionality. 
UAVs and other combat robotics have been allowed to develop fairly free from international regulation, as weapon systems under absolute human control. They have not developed free from scrutiny however, as their use in targeted killing operations has raised their notoriety on an IHL and LOAC basis unrelated to their level of autonomy. UAVs have also raised another point that is highly relevant to potential autonomous weapon systems by lowering the cost of war for those in possession of them. By allowing a nation to wage remote warfare, the political, fiscal, and human life costs of war are dramatically decreased, placing the nation without remote-controlled robotics at a much higher overall risk in a conflict. This process effectively lowers the threshold for going to war and engaging in combat operations-a quality that would be shared by the deployment of autonomous weapon systems. The UAV debate over targeted killing operations, and the inherent lowering of the threshold for conducting such operations, has directly impacted the debate over autonomous weaponry. By showing the inhumanity, reactively, of targeted killings conducted by UAVs, including collateral damage, the prospect of any type of proactive ban on autonomous weapons can be advanced.

If the international community is to proceed with any type of ban on autonomous weapon systems, great care must be taken in the language used, and the specific areas regulated. Adaptive AI functions in general have the potential to enhance and improve a great number of areas of human life aside from combat functions, and a non-specific ban could potentially derail major improvements to human quality of life and health. Likewise, a ban focusing explicitly on military functions and technologies has the potential to prevent the development of dual-use technologies that could also contribute greatly to other areas of life. Even a ban that does not directly or indirectly impact non-military areas of research and development in adaptive AI may hinder future developments that could lead to a breakthrough in successfully programming IHL and the LOAC into an autonomous weapon system, rendering warfare to a permanent state of barbarity. Human rights organizations promote the use of precision munitions in order to mitigate collateral damage and casualties. Increased precision research and development should therefore be an area intentionally protected and preserved, even if it requires autonomy developments to improve. The same human rights organizations would be wise to recognize the dangers of an outright ban on autonomous weapons that would prevent their own cause from advancing.

Fortunately, according to $\mathrm{Hu}-$ man Rights Watch, who is the leading international organization promoting a ban on autonomous weaponry, the type of prohibitory ban on fully autonomous weapons being discussed and promoted within the international community "would in no way impede development of fully autonomous robotics technology" in general. ${ }^{36}$ Instead, the ban being considered would focus solely on the development of technologies explicit- 
ly designed for, and exclusively useful in, autonomous weapon systems, and would not affect autonomy research and development in other fields. This is an important clarification, as it prevents governments from essentially re- linquishing control and oversight of the technologies associated with adaptive AI and autonomy. Table 1 illustrates the actual and potential developments for autonomous systems:

Table 1. Projected capabilities for autonomous systems. Copyright (2016), Defense Science Board, Summer Study on Autonomy. ${ }^{38}$ (Explains the current, near-future, and potential long-term developments in autonomy research and development.)

\section{Table 1 Projected capabilities for autonomous systems}

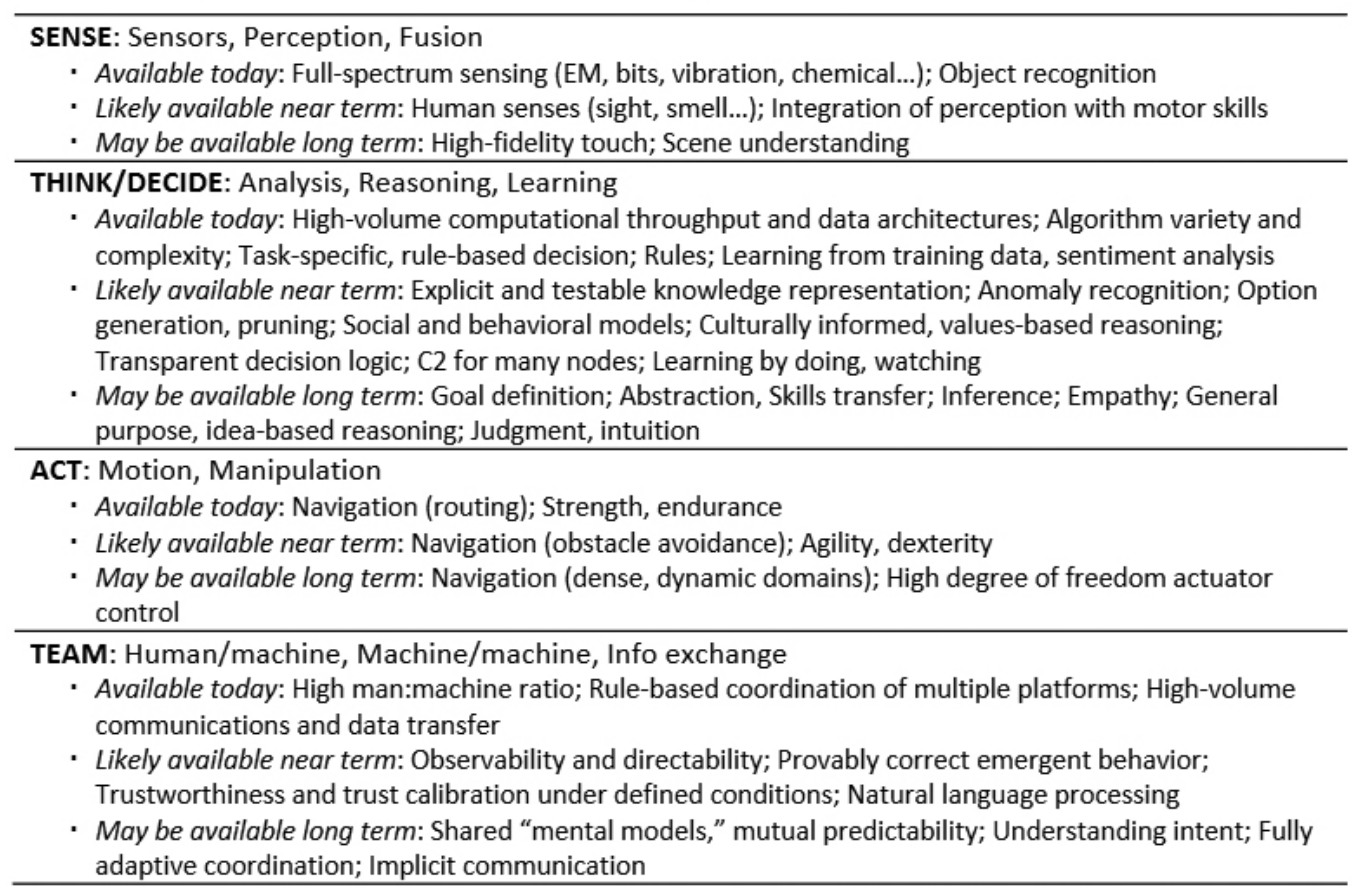

A more general ban would most likely result in non-governmental organizations taking the lead, publicly or secretly, and advancing their own programs of autonomy and adaptive AI. Such a development would subsequently be the most likely path towards technologies of this sort ending up on the black market, or in the hands of terrorist organizations. People will pursue these developments regardless of legality now that their existence is possible. Nations and the international community ignoring this fact will only put the world at a disadvantage moving into the future.

One major argument against autonomous weapon systems is that a system with adaptive AI functions may adapt to its environment in ways which contradict legal or moral parameters, and that if a system is truly autonomous, it may not be able to be stopped. This 
can be mitigated through a temporal or metric operational limit once activated, which causes an automatic shutdown of the machine unless re-authorized to continue engagements periodically. This would not require continuous communications to remain in place, and so would avoid the pitfalls associated with constant communications. Burst transmissions could be utilized in both directions in order to decrease communication risks and to increase the fluidity of operations by re-authorizations being sent before shutdown points. Establishing these shutdown parameters would also eliminate all of the risks associated with losing control of the asset physically or losing contact. The system would still be autonomous, it would still adapt to its environment, and it would retain all of the capabilities associated with distance-based conflict acting as a major force multiplier to enhance the lethality of combat operations, but without many of the associated risks.

\section{Conclusions}

$\mathrm{I}$ $\mathrm{n}$ order to move the international debate on autonomous robotics designed for warfare in a forward and positive direction, it is clear that several conditions must be met. First, the proposed actions must be framed in a reactive manner, based on either direct evidence pertaining to the systems being discussed, or principally, based on similar historical precedents. Second, the majority of the international community, meaning state governments and their people, must generally agree on both the explicit definitions of autonomous weapon systems, as well as the need for, or at least the acceptance of, the proposed solution. Finally, all of the major powers of the world and all of the leading autonomy-related technology nations must be participants in the solution. The United States has opened the door for the necessary language to be adopted which would allow further research and development in almost every critical area, but while still essentially banning the development of autonomous weapon systems specifically designed to apply lethal force to human targets without positive human control. ${ }^{37}$ The 2012 US Department of Defense Directive 3000.09 can be used as a guideline for the necessary language to promote an effective international action on autonomy capable of achieving significant impact.

The international community should proceed, carefully, with a proactive international action from a reactive point of view based on real historical precedents. This can be achieved by focusing primarily on the lowering of the threshold for engaging in combat operations and combining it with the moral dereliction that would be encompassed in a decision to delegate powers over the life and death of human beings to machines. By using the historical principles of The Hague VIII Convention and the Mine Ban Treaty, which clearly identify the differences between human controlled weapons and non-human controlled weapons, the international community can create the illusion of a reactive international precedent to promote a proactive international action 
with regards to regulating or banning autonomous weapon systems. Targeted killing operations by UAVs can be used to show the enhanced combat abilities that come with such technologies, as well as the drastic unbalancing of risk assumption between those with and those without such technologies.

By combining the historical precedents of the autonomous lethal targeting inherent in contact mines with the modern-day autonomous mobility applications, sufficient language can be developed in an explicit and limited ban on autonomous weaponry technologies. In order for such weapon systems to even exist in compliance with IHL and the LOAC, further developments must be made in adaptive AI functions, sensor capabilities, and programming capacities. Because of the eventual po- tential for these developments to reach the necessary levels for machines to exhibit the necessary IHL levels of distinction and proportionality, a clause should be included in any ban which acknowledges this eventual possibility. By explicitly defining autonomous weapons, the international community can allow research and development to continue in the fields which may eventually lead to the required developments, while still achieving the desired stigmatization of the autonomous weaponry field and preventing development and proliferation of such technologies. Mankind will move forward, and in such a major technology revolution, it is important to protect development while controlling advancements in order to maintain a stable world for the future.

Joshua E. Duke served as a US Army intelligence analyst, including 24 months in Iraq in support of Operation Iraqi Freedom I, II, III, and IV. He holds a BA in intelligence studies with a concentration in counterintelligence from American Military University and is now serving in the United States Marine Corps. Joshua Duke's research focuses on national security and intelligence, including new approaches to counterterrorism using counterintelligence-based models; autonomous weaponry developments and their applications to international law, armed conflict, and US national security; and the future impacts of the space domain on global economics, intelligence operations, and US national security. He is also the author of "The Counterterrorism Conundrum: Understanding Terrorist Organizations, Ideological Warfare and Strategies for Counterintelligence-Based Counterterrorism." Global Security and Intelligence Studies 6, No. 1 (Spring/Summer 2021): 125-147; "Inside the Wire at 1st Marine Division Schools, Camp Pendleton" (Military Appreciation Resource Magazine, MCB Camp Pendleton, Online October 2020; Print January 2021); "Cyber World War: The People's Republic of China, Anti-American Espionage, and the Global Cyber Arms Race" (Global Security Review, 2020); "Conflict and Controversy in the Space Domain: Legalities, Lethali- 
ties, and Celestial Security" (Wild Blue Yonder, Air University, 2020); "Paid to Kill: An Examination of the Evolution of Combatants for Hire" (Global Security Review, 2020); and "From Missiles to Microchips: Nation-States, Non-State Actors, and the Evolution of Intelligence" (Global Security Review, 2020).

\section{Endnotes}

1 United Nations, "Treaty on Principles Governing the Activities of States in the Exploration and Use of Outer Space, Including the Moon and Other Celestial Bodies," United States Department of State (1967).

2 United Nations, "Convention on the Prohibition of the Development, Production, Stockpiling and Use of Chemical Weapons and on their Destruction," United Nations Office for Disarmament Affairs (1993).

3 "Laws of War: Laying of Automatic Submarine Contact Mines (Hague VIII); October 18, 1907," The Avalon Project (1907).

4 "Laws of War."

5 United Nations, "Convention on the Prohibition of the Use, Stockpiling, Production and Transfer of Anti-Personnel Mines and on their Destruction, 18 September 1997," International Committee of the Red Cross (1997).

6 Department of Defense, "Summer Study on Autonomy," Defense Science Board (2016).

7 De Greef, Tjerk and Alex Leveringhaus, "Design for Responsibility: Safeguarding Moral Perception Via a Partnership Architecture," Cognition, Technology \& Work 17, no. 3 (2015), 321.

8 General Atomics, "MQ-9 Reaper/Predator B Data Sheet," General Atomics Aeronautical (2017), 2.

9 Heather Roff, "Meaningful Human Control or Appropriate Human Judgement? The Necessary Limits on Autonomous Weapons," Arizona State University (2016), 1-2.

10 Roff, "Meaningful Human Control or Appropriate Human Judgement," 1-2.

11 Kenneth Anderson and Matthew Waxman, "Law and Ethics for Autonomous Weapon Systems: Why a Ban Won't Work and How the Laws of War Can," The Hoover Institution (2013), 5-8.

12 Roff, "Meaningful Human Control or Appropriate Human Judgement," 1-2.

13 Noel Sharkey, "Towards a Principle for the Human Supervisory Control of Robot Weapons," Politica \& Societa 2 (2014), 10-12.

14 Sharkey, "Towards a Principle for the Human Supervisory Control of Robot Weapons," 12. 
15 Sharkey, "Towards a Principle for the Human Supervisory Control of Robot Weapons," 12.

16 Noel Sharkey, “The Evitability of Autonomous Robot Warfare," International Review of the Red Cross 94 (2012), 791-796.

17 International Human Rights Clinic, "Advancing the Debate on Killer Robots: 12 Key Arguments for a Preemptive Ban on Fully Autonomous Weapons," Human Rights Watch (2014), 4-8.

18 International Human Rights Clinic, "Advancing the Debate on Killer Robots," 4-8.

19 Peter Asaro, "On Banning Autonomous Weapon Systems: Human Rights, Automation, and the Dehumanization of Lethal Decision-Making," International Review of the Red Cross 94 (2012), 700-701.

20 Asaro, “On Banning Autonomous Weapon Systems," 708-709.

21 Heather Roff, "Lethal Autonomous Weapons and Jus Ad Bellum Proportionality," Case Western Reserve Journal of International Law 47 (2015), 51-52.

22 Ronald Arkin, "Lethal Autonomous Systems and the Plight of the Non-Combatant," AISB Quarterly 137 (2013), 3-4.

23 Arkin, "Lethal Autonomous Systems and the Plight of the Non-Combatant," 5-6.

24 Arkin, "Lethal Autonomous Systems and the Plight of the Non-Combatant," 5-6.

25 Sharkey, “The Evitability of Autonomous Robot Warfare, 799.

26 Asaro, "On Banning Autonomous Weapon Systems," 709.

27 Anderson and Waxman, "Law and Ethics for Autonomous Weapon Systems," 5-8.

28 Anderson and Waxman, "Law and Ethics for Autonomous Weapon Systems," 5-8.

29 Arkin, "Lethal Autonomous Systems and the Plight of the Non-Combatant," 6-7.

30 Anderson and Waxman, "Law and Ethics for Autonomous Weapon Systems," 27.

31 Christof Heyns, “A/HRC/23/47,” United Nations Human Rights Council (2013).

32 United Nations, "Protocol on Blinding Laser Weapons (Protocol IV to the 1980 Convention), 13 October 1995," International Committee of the Red Cross (1995).

33 United Nations, "Treaty on Principles Governing the Activities of States in the Exploration and Use of Outer Space, Including the Moon and Other Celestial Bodies."

34 United Nations, "Convention on the Prohibition of the Use, Stockpiling, Production and Transfer of Anti-Personnel Mines and on their Destruction, 18 September 1997."

35 Sharkey, "Towards a Principle for the Human Supervisory Control of Robot Weapons," 10-12. 
36 International Human Rights Clinic, "Advancing the Debate on Killer Robots," 26.

37 Department of Defense. "DoDD 3000.09: Autonomy in Weapon Systems." Department of Defense (2012), 2-3.

38 Department of Defense, "Summer Study on Autonomy," Defense Science Board (2016), 11. 